\title{
Virtual Reality Exhibition Platform
}

\author{
Gicu Calin Deac, Crina Narcisa Georgescu, Cicerone Laurentiu Popa, \\ Mihalache Ghinea \& Costel Emil Cotet
}
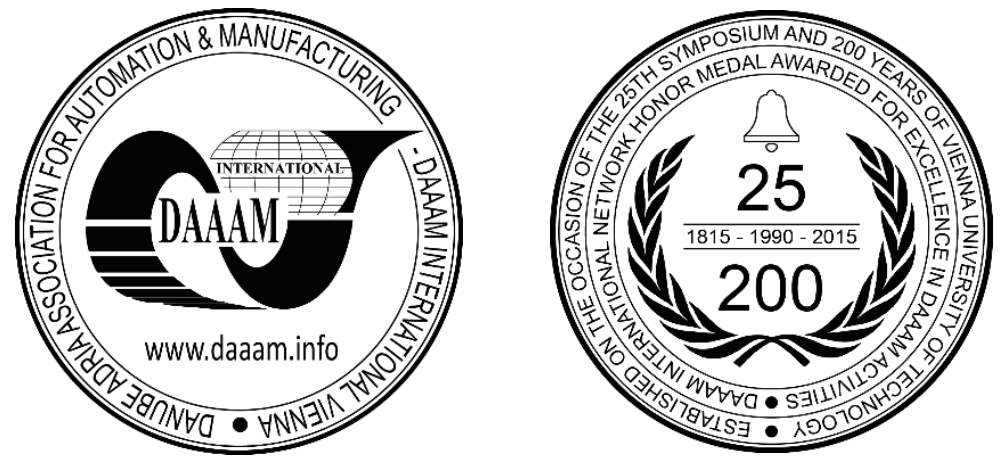

This Publication has to be referred as: Deac, G[icu] C[alin]; Georgescu, C[rina] N[arcisa]; Popa, C[icerone] L[aurentiu]; Ghinea, M[ihalache] \& Cotet, C[ostel] E[mil] (2018). Virtual Reality Exhibition Platform, Proceedings of the 29th DAAAM International Symposium, pp.0232-0236, B. Katalinic (Ed.), Published by DAAAM International, ISBN 978-3-902734-20-4, ISSN 1726-9679, Vienna, Austria

DOI: $10.2507 / 29$ th.daaam.proceedings.033

\begin{abstract}
Companies, professionals and industry experts are using trade shows to share information and to build long-lasting business relationships. A trade show could have some disadvantages such as: higher price, difficulty to attend for potential partners due to distance, cost and time. An alternative could be the use of virtual reality exhibitions. In this paper, research results for developing a virtual reality exhibition platform are presented. The platform provides collaborative and advertisement tools enabling the possibility to interact and run complex activities remotely in a virtually immersive environment. The authors have developed some tools that extends the High Fidelity platform capabilities by designing, modelling and texturing the virtual environment, consisting in a futuristic city, a large exhibition pavilion and the exhibition booths using Maxon Cinema 4D and Substance Painter for modelling.
\end{abstract}

Keywords: trade shows; virtual reality; exhibition platform; collaborative tools

\section{Introduction}

Virtual Reality (VR) is a technology that allows the user to interact with a computer simulated environment, via Head Mounted Display (HMD) or through CAVE stereoscopic projection systems. In this computer-generated simulation, the users have the opportunity to experience a world that is not physical and is not real, but can be close to real world, or can transcend reality into a futuristic and fantastic representation [1][2]. The paradigm of the Fourth Industrial Revolution, described by Industry 4.0's parent, Klaus Schwab, explains that this evolution eliminates physical, digital and biological limits in the new industrial era. The challenge behind this new industrial revolution is to integrate physical, cybernetic and Internet objects (IoT), Big Data and cloud computing, robotics, artificial intelligence and additive manufacturing systems into the Industry 4.0 paradigm. Schwab requires for responsible leaders and citizens to "together shape a future that works for all by putting people first, empowering them and constantly reminding ourselves that all of these new technologies are first and foremost tools made by people for people." In this environment, not only the employee profile implies a "hard" melting with "soft" skills: competences acquired during the professional training and a constellation of skills and personal qualities but some virtual environments include additional sensory information, such as audio, haptic systems and smell [3]. 
Users interact with the virtual environment through standard input devices such as mouse, keyboard, multimodal devices (wired glove, extension arm - arm boom, omnidirectional treadmill, Leap Motion Controller or Nimble VR). By including concepts and elements of real life in the virtual world, live streamed images for example, we can talk about augmented reality [4]. Our research focused on expanding the capabilities of a virtual reality platform in order to create an immersive and collaborative environment suitable for simulating trade shows and exhibitions.

Trade shows are used by companies, professionals and industry experts to share information and to build long-lasting business relationships. Even if the exhibitions have many advantages for companies and professionals, a few disadvantages could also be identified, such as: higher price, difficulty to attend for many potential partners caused by distance, cost and time. A virtual reality exhibition will overcome this disadvantage, being accessed remotely, around the world, prices of a virtual exhibition stand is minimal and the tools available for promoting products and services could be extended. Such an exhibition could be also permanent, not just for few days as in the case of the real exhibition. Considering this, a virtual exhibition platform that could accommodate big events in a cheaper, interactive and spectacular way was developed by our team.

\section{The virtual reality exhibition platform}

To develop such a complex platform, we needed first to select a proper engine to start with. After a study of the options currently available on the market, we have selected the High-Fidelity engine, an open-source engine that enables the expansion and development by exposing the engine core by JavaScript and QML (https://highfidelity.com) [5]. This engine allows the importing of 3D models in FBX and OBJ format and fully support PBR materials and procedural textures. The engine allows also importing of rigged 3D characters as avatars and have a good physics engine for complex simulations and interaction [6][7].

To sustain an exhibition event, our team have developed some tools that extends the High Fidelity platform capabilities. We have started by designing, modeling and texturing the virtual environment, consisting in a futuristic city, a large exhibition pavilion and the exhibition booths. This 3D models were modelled in Maxon Cinema 4D and textured using Substance Painter. Having all this in place we have created the automations for door opening, for escalator and for sitting chairs (figure 1). We have developed also the software for integrations, based on JavaScript and QML. For some tools we have a MySQL database driven by a PHP server application. Some tools are designed on Node.js and Socket.io and allows Realtime interactions.

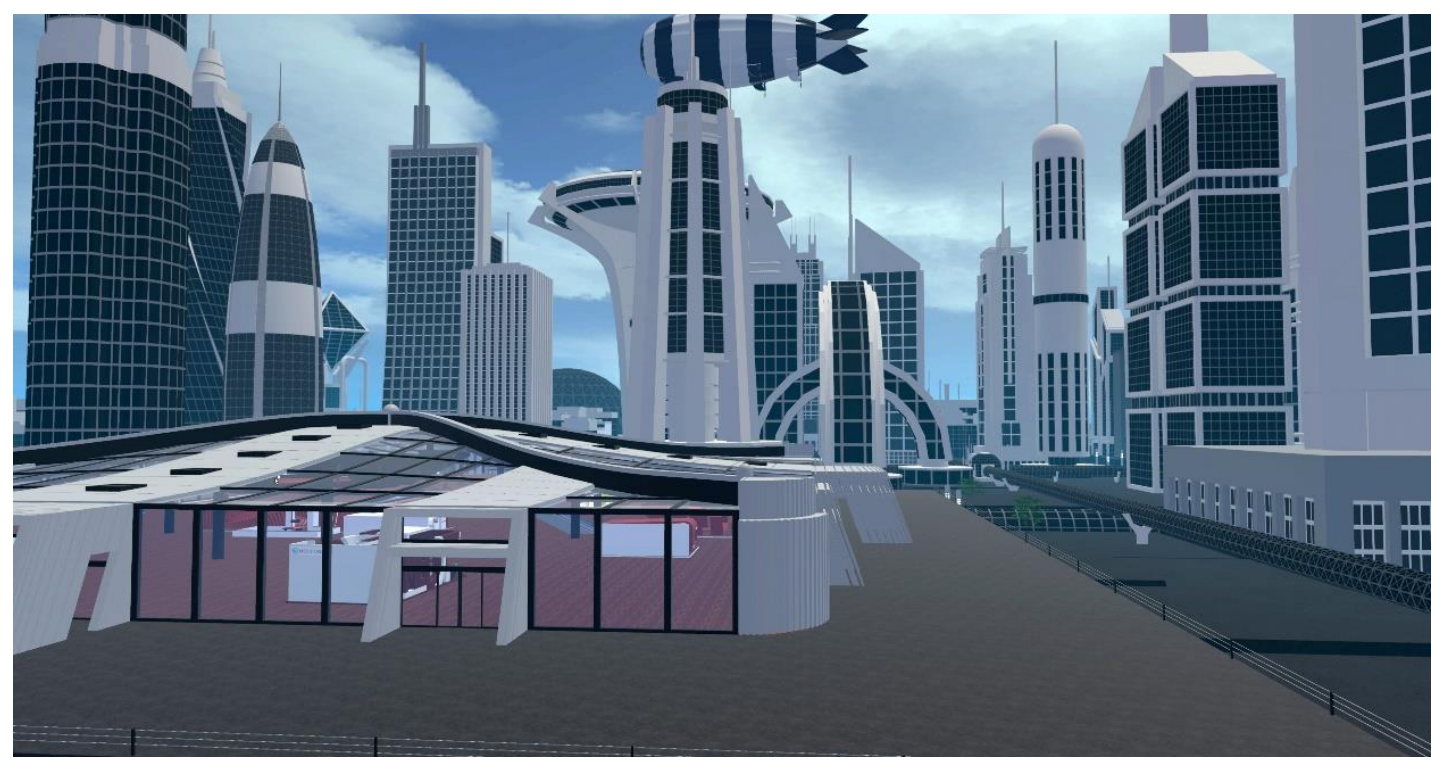

Fig. 1. Virtual city and the exhibition pavilion

In the next section, the main tools developed by our team on the virtual platform are presented:

1. Live audio communication. A high-fidelity audio interface with a surround mixer is part of the platform. This allows for a realistic communication between users.

2. Customizable 3D avatars with VR tracking system and default gesture desktop interface (figure 2). A realistic simulation system for avatar movement and 3D tracking of user movement is integrated in the platform, using HTC Vive and Oculus Rift trackers or Leap-Motion controller. For improving the transmitting of nonverbal communication and body language cues. An advanced gesture interface is available, in case of desktop mode use and for those who don't have tracker- contact list. Users can exchange contacts by a handshake between avatars. 
3. Interactive teleportation system. With the help of a portal system, the user can teleport inside a domain and from one domain to another.

4. Chat text - application based on JavaScript and Node.js that allows text-based communication between users. Emoticons, image and video sharing and portal dropper can be used (the coordinates of a place can be generated and this generated link can be clicked).

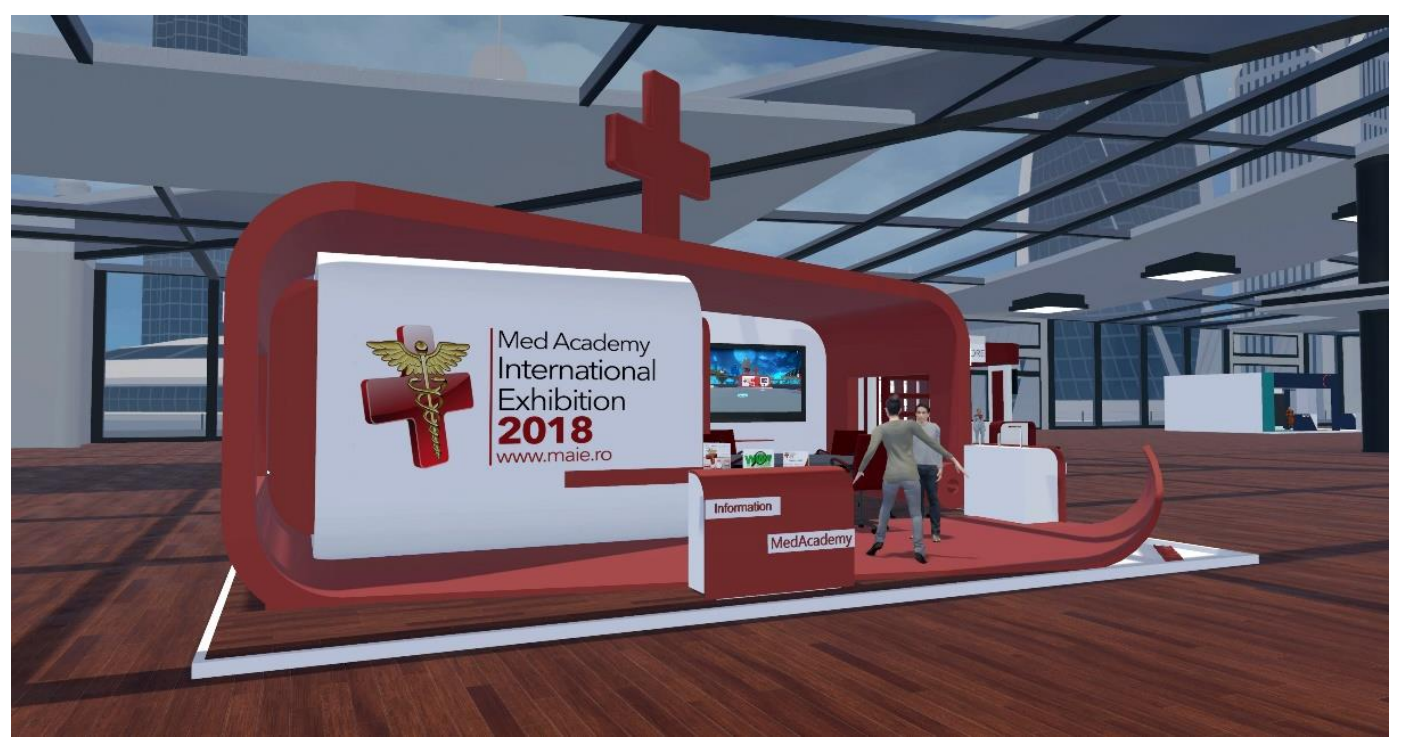

Fig. 2. Customizable 3D avatars

5. Visitors' inventory system. The visitors can collect brochure and business cards, catalogues, contacts etc. by clicking on the icons presented in the exhibition stands. Inside the VR platform users can access the inventory whenever they want. They can also use an external web application, based on user name authentication (figure 3)

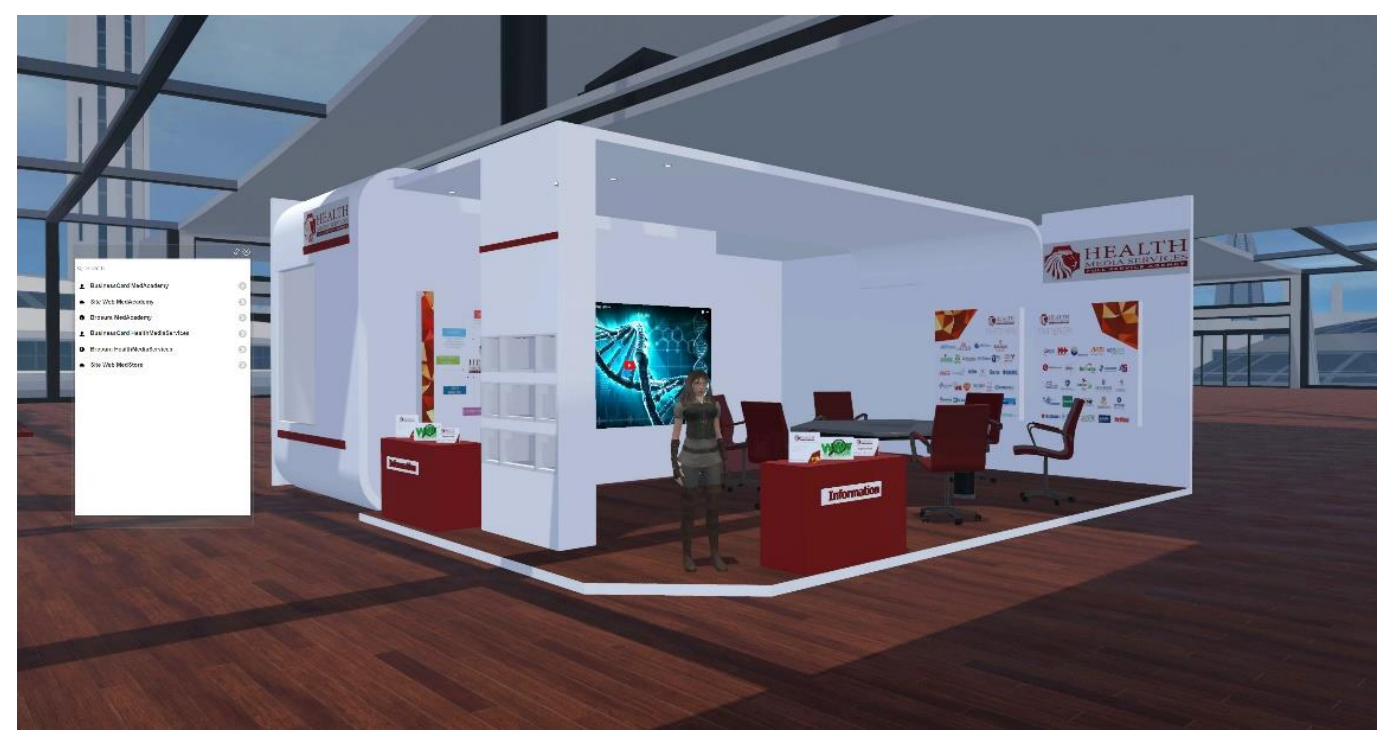

Fig. 3. Inventory system for catalogues, brochure and business cards

6. Mobile and Standalone video conferencing - JavaScript, WebRTC multiuser application allowing audio-video communication for the users inside VR or between VR and real world. Screen sharing and video sharing from YouTube and Vimeo and text chat can be used.

7. Web sites and web applications integrated into VR using a 3D Web entity, content from web and web applications can be included and accessed in VR.

8. Snapshots. Using this app the users can create photos in the virtual environment and can share them in their network of friends on Facebook or Twitter. The snapshots can be printed also in VR as 3D framed photo. 
9. A virtual video camera can be used in the VR environment and the user can export videos and 360 panoramas.

10. Multimedia presentation system, including slides, video, polls, live webcam streaming. Via a Node.js WebRTC application users can upload slides and videos to be presented in sync to other users (figure 4).

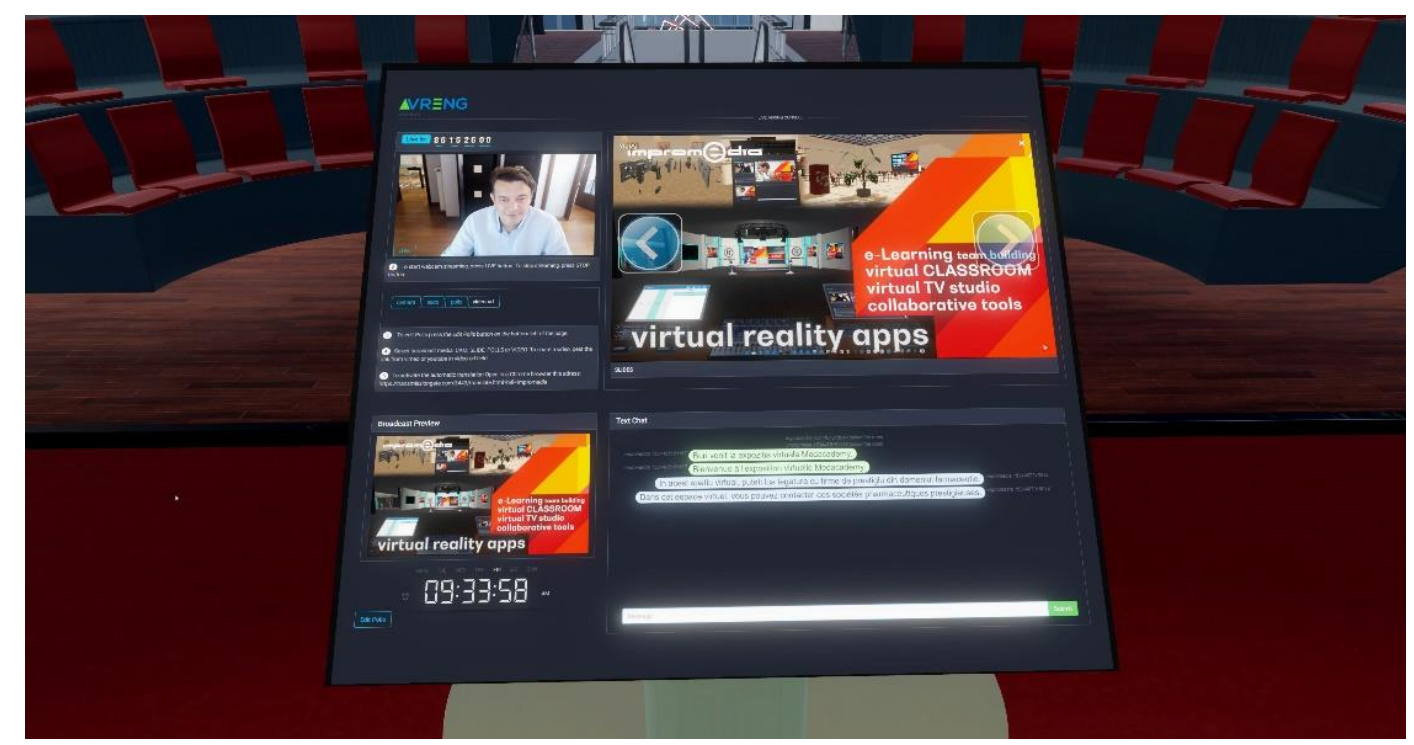

Fig. 4. Multimedia presentation system

11. Screen share -live PC screens in VR can be displayed.

12. Simultaneous audio language translation system. A WebRTC JavaScript application using Google API for translation, allowing real time instant translation from / to 200 different languages (figure 5).

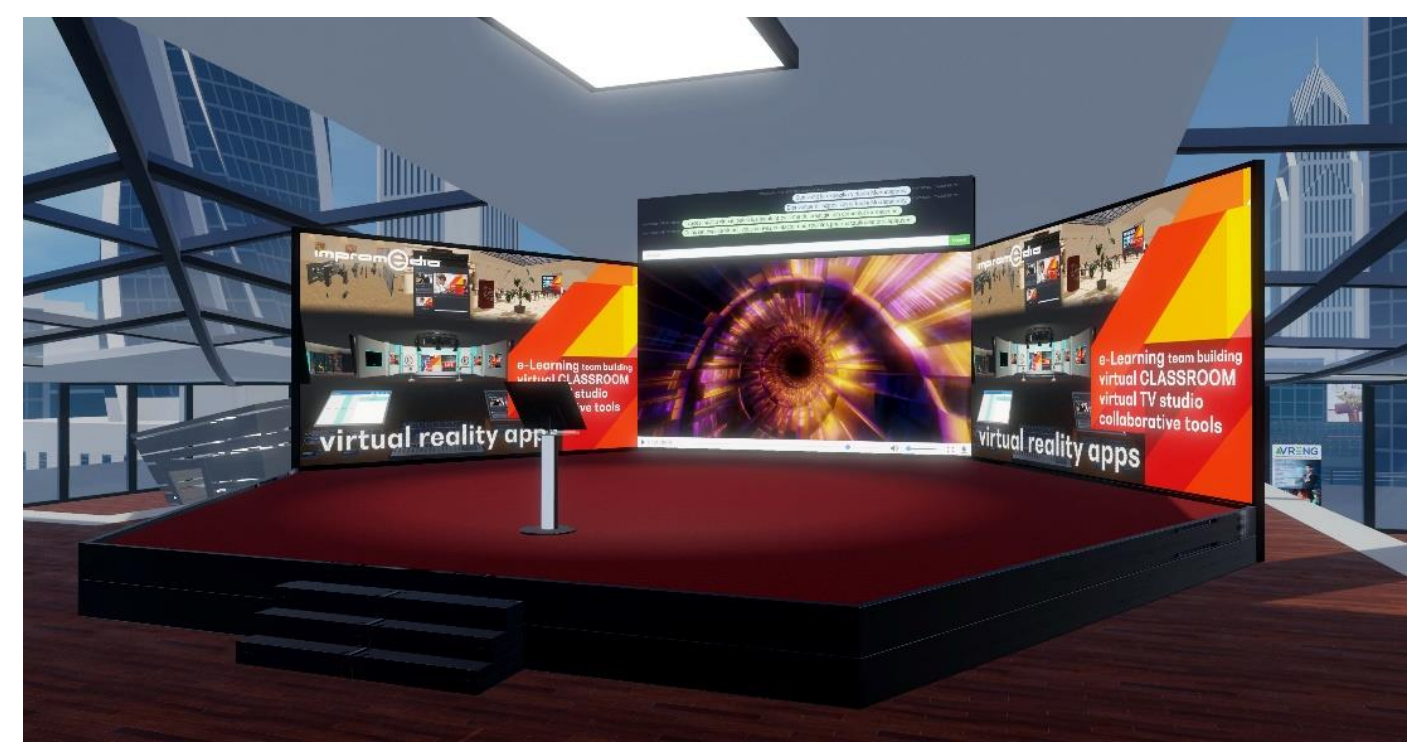

Fig. 5. Aula with multimedia and automatic translation system

13. WebRTC live streaming allowing live broadcasts in the VR environment, from VR to Web and from outside to VR.

14. Augmented reality system - through the scanning of augmented objects like posters, catalogues or business cards, $3 \mathrm{D}$ objects or video files with the VR phone (figure 6).

Developing such a platform from scratch was a challenge, albeit a chance to test our competencies and results on a complex prototype. After the system modelling, the simulation of various scenarious confirm the system performances in presenting various industry 4.0 applications according with the evolution of products into intelligent, connected deviceswhich are increasingly embedded in broader systems [8]. 


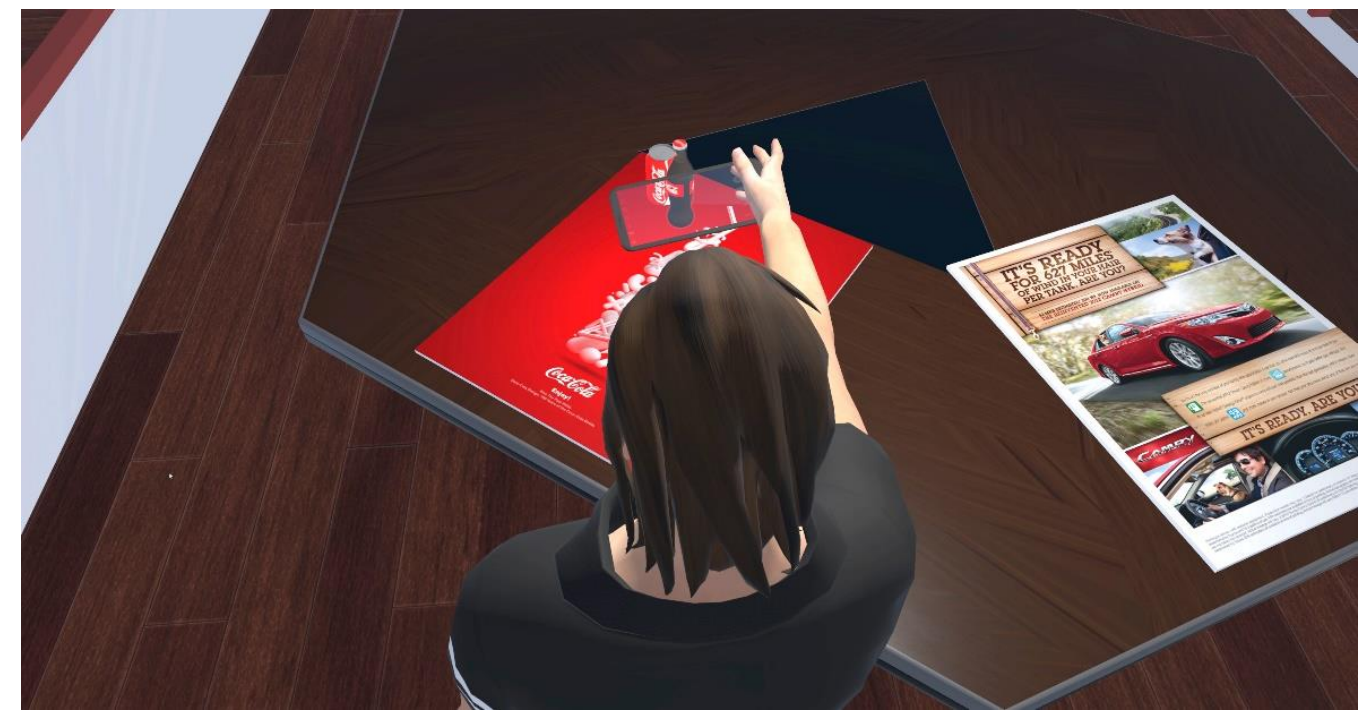

Fig. 6. Augmented Virtual Reality

\section{Conclusion}

All smart, connected products, from home appliances to industrial equipment, share three core elements: physical components (such as mechanical and electrical parts); smart components (sensors, microprocessors, data storage, controls, software, an embedded operating system, and a digital user interface); and connectivity components (ports, antennae, protocols, and networks that enable communication between the product and the product cloud, which runs on remote servers and contains the product's external operating system). Smart, connected products require a whole new supporting technology infrastructure [9]. In this context using the JavaScript and qml API of the High Fidelity platform we have succeeded to extend his capabilities in order to create a truly social collaborative and immersive VR environment suitable for large exhibition events. The platform can be accessed by installing the HighFidelity engine interface from: https://highfidelity.com/download/thanks\#client. After the installation one can access the platform, pushing the GOTO button and typing the domain name called "medacademy". Current needs and practice in industrial engineering determined us to adapt the general VR environment and to develop specific algorithms for for manufacturing architectures presentations using digital twining. As can be noticed, our approach is not restrictive to specific industrial projects and in future research can be developed according with the advances in digital fabrication and the development of new manufacturing processes/technologies, thus responding to the current trend of industry 4.0.

\section{Acknowledgments}

We want to thank the HighFidelity community for collaboration and support.

\section{References}

[1] Gartner Research (2008). Hype Cycle for Emerging Technologies, Available from: http://www.gartner.com/it/page.jsp?id=739613 Accessed: 2018-08-15

[2] Martirosov, S. \& Kopecek, P. (2017). Virtual Reality and its Influence on Training and Education - Literature Review, Proceedings of the 28th DAAAM International Symposium, Vienna, Austria, ISSN 1726-9679, ISBN 978-3902734-11-2, B. Katalinic (Ed.), pp.0708-0717, Published by DAAAM International, Vienna, DOI: 10.2507/28th.daaam.proceedings. 100

[3] Cotet, G.B; Balgiu, B.A \& Zaleschi, V.C. (2017). Assessment procedure for the soft skills requested by Industry 4.0, The 8th International Conference on Manufacturing Science and Education - MSE 2017 "Trends in New Industrial Revolution", MATEC Web of Conferences, Volume 121, Article Number 07005, eISSN: 2261-236X

[4] Burdea, G., Coiffet, Ph. (1995). La realite Virtuelle, Ed. Hermes, Paris

[5] High Fidelity. Available from: www.highfidelity.com Accessed: 2018-07-10

[6] Chaillou, C., Froumentin, M. (1997). La Synthese d'images, Ėcole Universitaire d'ingenieurs de Lille, France

[7] Ștefănescu, B. (2000). Tehnici moderne de generare a mediilor virtuale prin sinteză grafică asistată de calculator, Ed. ICI, Bucharest

[8] Debevec M., Simic M., \& Herakovic N. (2014). Virtual Factory as an Advanced Approach for Production Process Optimization. International Journal of Simulation Modelling IJSIMM, Vol. 13, No. 1, pp.66-79, ISSN 1726-4529

[9] Porter M.E., Heppelmann J.E. (2015). How Smart, Connected Products Are Transforming Companies, Harvard Business Review, October 2015, 1-19, HBR.org 